\title{
ADAPTIVE DEVELOPMENT OF SVSF FOR A FEATURE- BASED SLAM ALGORITHM USING MAXIMUM LIKELIHOOD ESTIMATION AND EXPECTATION MAXIMIZATION
}

\author{
Heru SUWOYo ${ }^{1,3}$, Yingzhong Tian ${ }^{1,2}$, Wenbin WANG ${ }^{4}$, Long Li ${ }^{1,2}$, \\ ANDi AdRIANSYAH ${ }^{3 *}$, FengFeng XI ${ }^{5}$, GUANGJIE YUAN ${ }^{1,2}$ \\ ${ }^{I}$ School of Mechatronic Engineering and Automation,Shanghai University, Shanghai, China \\ ${ }^{2}$ Shanghai Key Laboratory of Intelligent Manufacturing and Robotics, Shanghai University, \\ Shanghai, China \\ ${ }^{3}$ Department of Electrical Engineering, Universitas Mercu Buana, Jakarta, Indonesia \\ ${ }^{4}$ Mechanical and Electrical Engineering School, Shenzhen Polytechnic, Guangdong, China \\ ${ }^{5}$ Department of Mechanical Aerospace, and Industrial Engineering, Ryerson University, \\ Toronto, Canada
}

*Correspondingauthor: andi@mercubuana.ac.id

(Received: $18^{\text {th }}$ March 2020; Accepted: 23 ${ }^{\text {rd }}$ October 2020; Published on-line: $4^{\text {th }}$ January 2021)

\begin{abstract}
The smooth variable structure filter (SVSF) has been considered as the robust estimator. Like other filters, the SVSF needs an accurate system model and known noise statistics to approximate the posterior state. Unfortunately, the system cannot be accurately modeled, and the noise statistic is unknown in the real application. For these reasons, the performance of SVSF might be decreased or even led to divergence. Therefore, the enhancement of SVSF is required. This paper presents an Adaptive SVSF. Initially, SVSF is smoothed. To provide the ability to estimate the noise statistic, ASVSF is then derived based on maximum likelihood estimation (MLE) and expectation-maximization (EM). Additionally, the unbiased noise statistic is also approached. However, its covariance is complicatedly formulated. It might cause a negative definite symmetric matrix. Therefore, it is tuned based on the innovation covariance estimator (ICE). The ASVSF is designed to solve the online problem of Simultaneous Localization and Mapping (SLAM). Henceforth, it is termed as the ASVSF-SLAM algorithm. The proposed algorithm showed better accuracy and stability compared to the conventional algorithm in terms of root mean square error (RMSE) for both Estimated Path Coordinate (EPC) and Estimated Map Coordinate (EMC).
\end{abstract}

ABSTRAK: Penapis struktur bolehubah lembut (SVSF) telah dianggap sebagai penganggar teguh. Seperti penapis lain, SVSF memerlukan model sistem yang tepat dan statistik hingar yang diketahui bagi menganggar keadaan posterior. Malangnya, sistem tidak dapat dimodelkan dengan tepat dan statistik hingar tidak diketahui dalam aplikasi sebenar. Atas sebab-sebab ini, prestasi SVSF mungkin berkurangan, bahkan berbeza. Oleh itu, memperbaharui SVSF adalah perlu. Kajian ini adalah mengenai SVSF Mudah Suai. Pada awalnya, SVSF dilembutkan. Bagi menyediakan keupayaan anggaran statistik hinggar, ASVSF dihasilkan terlebih dahulu berdasarkan anggaran kemungkinan maksimum (MLE) dan maksimum-harapan (EM). Tambahan, statistik hinggar yang tidak berat sebelah juga dibuat. Walau bagaimanapun, rumusan formula kovarians ini adalah kompleks. Ini mungkin menyebabkan matriks simetri menjadi negatif. Oleh itu, ia diselaraskan berdasarkan penganggar kovarians inovasi (ICE). ASVSF dibina bagi menyelesaikan masalah dalam talian Penempatan dan Pemetaan Serentak (SLAM) dalam talian. Oleh itu, ia disebut sebagai 
algoritma ASVSF-SLAM. Algoritma yang dicadangkan ini menunjukkan ketepatan dan kestabilan yang lebih baik berbanding algoritma konvensional dari segi ralat punca min kuasa dua (RMSE) bagi kedua-dua Koordinat Anggaran Laluan (EPC) dan Anggaran Koordinat Peta (EMC).

KEYWORDS: SLAM, ASVSF, MLE, EM, ICE

\section{INTRODUCTION}

It has been stated that the role of a consistent map of a complex environment can significantly help the robot to conduct the navigation task [1], [2]. However, the robot is commonly blind from this environment. Therefore, the robot should be completed to construct the map used to navigate itself and concurrently locate the position of the robot used [1] for the initial base of the mapping task. Theoretically, it is known as Simultaneous Localization and Mapping (SLAM) problem) [3]-[6]. Due to this widespread problem's challenges, the SLAM has been attracting much attention from different researchers. As the manner to fulfill the objective to estimate the robot path and static map, the estimation based on the probability principle has been frequently proposed, such as Extended Kalman Filter (EKF) [5]-[9]. The use of EKF has been limited because of the consistency issue [10].

For this reason, the Smooth Variable Structure Filter (SVSF) [10]-[13] is often chosen as the alternative filtering method of EKF. The SVSF is relatively considered a new predictorestimator that adopts the sliding mode [13]-[15]. The switching gain is utilized as a way to reach the convergence by forcing the estimated values to always on the boundary of the truth estimates. Similar to the former implementation of EKF, which keeps the noise statistic to be invariant under the step increment, SVSF has been proven to successfully solving the featurebased online SLAM problem [16]-[19]. Fundamentally, the SVSF requires the accurate system model and known characteristic of the noise statistic. Unfortunately, these orders are often unavailable. Therefore, it still poses a risk of divergence and filter degradation quality [18], [20]. In order to cover this possibility, its conventional form needs to modify and enhance [21] [24].

The most effective way to improve is by adaptively approximating the unknown parameters based on the offline batch estimation. Generally, it can significantly tune the gain of SVSF [7], [15], [20], [22]. The use of this approach has been proven when used as the manner to improve the EKF [7], [8], [23], [25]-[29], Unscented Kalman Filter (UKF) [18], [30]-[34], and Cubature Kalman Filter (CKF) [24], [34]-[37]. There are some types of the method can be adopted, and two of them are used in this experiment, Maximum Likelihood Estimation (MLE) [7], [18], [31], [38]-[41] and the working principle of ExpectationMaximization (EM) [7], [40]-[43]. The process of obtaining the suboptimal solution under these creations seem to unobservable. For this reason, the improved SVSF expanded based on the one-step smoothing point is involved [7], [20], [44]. It is adopted to proceed with the derivation process under MLE [15]. These processes aim produces the time-varying formulation relative to the noise statistic and its covariances. It gives the form with high complexity; thus, it is compactly reduced. However, it was not strong enough to guarantee positive definite covariance. Accordingly, the Innovation Covariance Estimation (ICE) [7], [25], [38], [45], [46]is involved. Then it is further implemented as the feature-based SLAM algorithm of a wheeled mobile robot.

The rest parts of this paper are organized as follows. Section II presents the formulation of SVSF. Section III presents the adaptive SVSF with mathematical derivation. The first solution calculated using the MLE and EM, the enhanced SVSF, the unbiased MLE-estimator, its time- 
varying, and the addition of ICE. Section IV presents all the prerequisites to build the SLAM algorithm as well as presents the feature-based online SLAM algorithm referring to the proposed method. Section V presents a discussion about the results. Section VI presents the conclusion.

\section{CLASSICAL SMOOTH VARIABLE STRUCTURE FILTER}

Given a nonlinear Gaussian system as shown below,

$$
\left\{\begin{array}{c}
x_{k}=f\left(x_{k-1}, u_{k}\right)+\omega_{k-1} \\
z_{k}=h\left(x_{k}\right)+v_{k}
\end{array}\right.
$$

where $k$ is the discrete time index, $x \in \mathbb{R}^{n}$ refers to the state vector, $u$ is the control vector, and $z \in \mathbb{R}^{m}$ is the measurement vector. Meanwhile, $\omega \in \mathbb{R}^{n}$ is the additive noise following the process and $v \in \mathbb{R}^{m}$ is the additive noise of the measurement. Therefore, once $f($.$) and h($. are assumed as the transition and measurement function, respectively, the characteristic noise of Eq. (1) is expressed as follows

$$
\left\{\begin{array}{c}
E\left[\omega_{k}\right]=q_{k}, \operatorname{Cov}\left[\omega_{k}, \omega_{j}\right]=Q_{k} \delta_{k j} \\
E\left[v_{k}\right]=r_{k}, \operatorname{Cov}\left[v_{k}, v_{j}\right]=R_{k} \delta_{k j} \\
E\left[\omega_{k}, v_{j}\right]=0
\end{array}\right.
$$

where $\delta$ is well-known as the Kronecker delta function. Meanwhile, $E[$.$] is term used to$ indicate the expectation or mean and $\operatorname{Cov}[$,$] is used to indicate the covariance term.$

Once Eq. (1) and Eq. (2) are described, the summary of SVSF are chained as follows [12]

$$
\begin{aligned}
& \hat{x}_{k \mid k-1}=f\left(\hat{x}_{k-1 \mid k-1}, u_{k}\right)+q \\
& P_{k \mid k-1}=F P_{k-1 \mid k-1} F^{T}+Q \\
& e_{z, k \mid k-1}=z_{k}-h\left(\hat{x}_{k \mid k-1}\right)-r \\
& \psi=\left({\overline{\left(\left|e_{z, k \mid k-1}\right|_{a b s}+\gamma\left|e_{z, k-1 \mid k-1}\right|_{a b s}\right)}}^{-1} H P_{k \mid k-1}^{-1} H^{T}\left(H P_{k \mid k-1} H^{T}+R\right)^{-1}\right)^{-1} \\
& \operatorname{sat}\left[\psi^{-1} \overline{\overline{\bar{e}_{z, k \mid k-1}}}\right]=\left\{\begin{array}{cl}
1 & \psi^{-1} \overline{\overline{e_{z, k \mid k-1}}} \geq 1 \\
\psi^{-1} \overline{\overline{\bar{e}_{z, k \mid k-1}}}, & 1<\psi^{-1} \overline{\overline{e_{z, k \mid k-1}}}<-1 \\
-1 & \psi^{-1} \overline{\overline{e_{z, k \mid k-1}}} \leq-1
\end{array}\right. \\
& K_{k}^{S V S F}=H^{+}\left\{\overline{\overline{\left(\left|e_{z, k \mid k-1}\right|_{a b s}+\gamma\left|e_{z, k-1 \mid k-1}\right|_{a b s}\right)}} \circ \operatorname{sat}\left[\psi^{-1} \overline{\overline{e_{z, k \mid k-1}}}\right]\right\}\left[\psi^{-1} \overline{\overline{e_{z, k \mid k-1}}}\right]^{-1} \\
& \hat{x}_{k \mid k}=\hat{x}_{k \mid k-1}+K_{k}^{S V S F} e_{z, k \mid k-1} \\
& P_{k \mid k}=\left(I-K_{k}^{S V S F} H\right) P_{k \mid k-1}\left(I-K_{k}^{S V S F} H\right)^{T}+K_{k}^{S V S F} R_{k} K_{k}^{S V S F^{T}} \\
& e_{z, k \mid k}=z_{k}-h\left(\hat{x}_{k \mid k}\right)
\end{aligned}
$$

where, $P$ represents the state error covariance matrix, $F$ refers to the Jacobian matrix of $f($.$) and e_{z}$ is innovation of measurement error. The sign of $\overline{=}$ refers to the diagonal term, $\gamma$ refers to the constant indicating the convergence rate $0<\gamma_{i i} \leq 1, \psi$ refers to the boundary 
layer width, $Q \in \mathbb{R}^{n x n}$ correspondences to the covariance matrix of the noise statistic relative to the process and $R \in \mathbb{R}^{m x m}$ correspondences to the covariance matrix of the noise statistic relative to the measurement and $H$ is Jacobian matrix of the measurement. Meanwhile, the sign of.$^{+}$and $\circ$ are used to indicate the function of the pseudo-invers and Schur matrix multiplication, respectively. The stability of SVSF and its convergence to the existence of the subspace are satisfied if the absolute error about the posterior is smaller than the prior one [11], [12], [47]-[49]. Mathematically, it can be described as follows

$$
\left|e_{z, k-1 \mid k-1}\right|_{a b s}>\left|e_{z, k \mid k}\right|_{a b s}
$$

\section{ADAPTIVE SMOOTH VARIABLE STRUCTURE FILTER}

Assuming Eq. (1) contains the unknown parameters $\theta=(q, r, Q, R)$; then, using the Maximum Likelihood Estimation, its estimates $\hat{\theta}$ can be calculated as follows

$$
\hat{\theta}^{M L E}=\arg \max _{\theta}\left\{\ln \left[L\left(q, r, Q, R \mid Z_{k}, X_{k}\right)\right]\right\}
$$

Note that the likelihood function of $\theta$ is $L\left(q, r, Q, R \mid Z_{k}, X_{k}\right)$, which can be expanded as

$$
L\left(q, r, Q, R \mid Z_{k}, X_{k}\right)=p\left(Z_{k}, X_{k} \mid q, r, Q, R\right)=p\left(X_{k} \mid q, Q, r, R\right) p\left(Z_{k} \mid X_{k}, q, r, Q, R\right)
$$

Since $X_{k}=\left[x_{0}, \ldots, x_{k}\right], z_{k}=\left[z_{1}, \ldots, z_{k}\right]$, and Eq. (1) refers to the first-order of the Markov process, the factorized form of Eq. (14) is

$$
p\left(Z_{k}, X_{k} \mid \theta\right)=p\left[x_{0}\right] \prod_{i=1}^{k} p\left[x_{i} \mid x_{i-1}, q, Q\right] \prod_{i=1}^{k} p\left[z_{i} \mid x_{i}, r, R\right]
$$

Next, by considering that the prior knowledge complies with Gaussian distribution, then Eq. (15) can be rewritten as follows

$$
\begin{aligned}
p\left(Z_{k}, X_{k} \mid q, r, Q, R\right) & \\
= & \frac{1}{(2 \pi)^{-\frac{k(n+m)+n}{2}}}\left|P_{0}\right|^{-\frac{1}{2}}|Q|^{-\frac{k}{2}}|R|^{-\frac{k}{2}} \\
& \times \exp \left\{-\frac{1}{2}\left[\left\|x_{0}-\hat{x}_{0}\right\|_{P_{0}^{-1}}^{2}+\sum_{i=1}^{k}\left\|x_{i}-f\left(x_{i-1}\right)-q\right\|_{Q^{-1}}^{2}\right.\right. \\
& \left.\left.+\sum_{i=1}^{k}\left\|z_{i}-h\left(x_{i}\right)-r\right\|_{R^{-1}}^{2}\right]\right\}
\end{aligned}
$$

Then by taking logarithm Eq. (16), it yields

$$
\begin{aligned}
\ln \left[L\left(q, r, Q, R \mid Z_{k}, X_{k}\right)\right] & \\
& =-\frac{k(n+m)+n}{2} \ln (2 \pi)-\frac{1}{2} \ln \left(\left|P_{0}\right|\right)-\frac{k}{2} \ln (|Q|)-\frac{k}{2} \ln (|R|) \\
& -\frac{1}{2}\left[\left\|x_{0}-\hat{x}_{0}\right\|_{P_{0}^{-1}}^{2}+\sum_{i=1}^{k}\left\|x_{i}-f\left(x_{i-1}\right)-q\right\|_{Q^{-1}}^{2}+\sum_{i=1}^{k}\left\|z_{i}-h\left(x_{i}\right)-r\right\|_{R^{-1}}^{2}\right]
\end{aligned}
$$




\subsection{Expectation-Maximization (EM) Estimation}

According to Eq. (1) - Eq. (17) and aiming to estimate noise statistics about the process and measurement together with the corresponding covariances, the principle of ExpectationMaximization is involved. Estimating particular function based on EM are done by taking the expectation of the objective function, and sequentially maximizing its result [7], [40]-[43].

\subsubsection{Expectation Process (E-Step)}

The expectation process can be done by first taking the conditional expectation and sequentially equating the result to zero, as shown below.

$$
\begin{aligned}
E\left[\ln \left[L\left(q, r, Q, R \mid Z_{k}, X_{k}\right)\right]\right] & \\
& =-\frac{k(n+m)+n}{2} \ln (2 \pi)-\frac{1}{2} \ln \left(\left|P_{0}\right|\right)-\frac{k}{2} \ln (|Q|)-\frac{k}{2} \ln (|R|) \\
& -\frac{1}{2} E\left[\left\|x_{0}-\hat{x}_{0}\right\|_{P_{0}^{-1}}^{2}+\sum_{i=1}^{k}\left\|x_{i}-f\left(x_{i-1}\right)-q\right\|_{Q^{-1}}^{2}\right. \\
& \left.+\sum_{i=1}^{k}\left\|z_{i}-h\left(x_{i}\right)-r\right\|_{R^{-1}}^{2}\right]
\end{aligned}
$$

Now by supposing that

$$
C=-\frac{k(n+m)+n}{2} \ln (2 \pi)-\frac{1}{2} \ln \left(\left|P_{0}\right|\right)-\frac{1}{2} E\left[\left\|x_{0}-\hat{x}_{0}\right\|_{P_{0}^{-1}}^{2}\right]
$$

And applying Eq. (19) into Eq. (18), the compact form of Eq. (18) can be written as follows

$$
\begin{aligned}
E\left[\ln \left[L\left(q, r, Q, R \mid Z_{k}, X_{k}\right)\right]\right] & \\
& =C-\frac{k}{2} \ln (|Q|)-\frac{k}{2} \ln (|R|) \\
& -\frac{1}{2} E\left[\sum_{i=1}^{k}\left\|x_{i}-f\left(x_{i-1}\right)-q\right\|_{Q^{-1}}^{2}+\sum_{i=1}^{k}\left\|z_{i}-h\left(x_{i}\right)-r\right\|_{R^{-1}}^{2}\right]
\end{aligned}
$$

It is known that by definition $\|a\|_{b^{-1}}^{2}=a^{T} b^{-1} a$. Therefore, by applying the identity $\operatorname{tr}\left(a^{T} a\right)=\operatorname{tr}\left(a a^{T}\right)$, Eq. (20) can be calculated as

$$
\begin{aligned}
E\left[\ln \left[L\left(q, r, Q, R \mid Z_{k}, X_{k}\right)\right]\right] & \\
= & C-\frac{k}{2} \ln (|Q|)-\frac{k}{2} \ln (|R|) \\
& -\frac{1}{2} \sum_{i=1}^{k} E\left\{\operatorname{tr}\left[Q^{-1}\left(x_{i}-f\left(x_{i-1}\right)-q\right)\left(x_{i}-f\left(x_{i-1}\right)-q\right)^{T}\right]\right\} \\
& -\frac{1}{2} \sum_{i=1}^{k} E\left\{\operatorname{tr}\left[R^{-1}\left(z_{i}-h\left(x_{i}\right)-r\right)\left(z_{i}-h\left(x_{i}\right)-r\right)^{T}\right]\right\}
\end{aligned}
$$

\subsubsection{Maximization Process (M-Step)}

Up to this point, the unknown parameters relative to the noise can be approximated by maximizing $E\left[\ln \left[L\left(q, r, Q, R \mid Z_{k}, X_{k}\right)\right]\right]$. It can be done by calculating its partial derivative concerning all elements of the unknown parameter $\theta$ and equating it to zero. Correspondingly, the suboptimal of $\theta$ are determined as follows 


$$
\begin{gathered}
\hat{q}_{k}=\frac{1}{k} \sum_{i=1}^{k} x_{i \mid k}-f\left(x_{i-1 \mid k}\right) \\
\hat{r}_{k}=\frac{1}{k} \sum_{i=1}^{k} z_{i}-h\left(x_{i \mid k}\right) \\
\hat{Q}_{k}=\frac{1}{k} \sum_{i=1}^{k}\left(x_{i \mid k}-f\left(x_{i-1 \mid k}\right)-q\right)\left(x_{i \mid k}-f\left(x_{i-1 \mid k}\right)-q\right)^{T} \\
\hat{R}_{k}=\frac{1}{k} \sum_{i=1}^{k}\left(z_{i}-h\left(x_{i \mid k}\right)-r\right)\left(z_{i}-h\left(x_{i \mid k}\right)-r\right)^{T}
\end{gathered}
$$

According to Eq. (22) - Eq. (25), it can be evaluated that the multistep smoothing term of $x_{i \mid k}$ and $x_{i-1 \mid k}$ seems unobservable. Therefore, as the effort to proceed derivation process and prevent solution from inefficiency, $x_{i \mid k}$ and $x_{i-1 \mid k}$ are respectively replaced by $x_{i \mid i}$ and $x_{i-1 \mid i}$. Thus, the new forms of suboptimal solutions are obtained as

$$
\begin{gathered}
\hat{q}_{k}=\frac{1}{k} \sum_{i=1}^{k} x_{i \mid i}-f\left(x_{i-1 \mid i}\right) \\
\hat{r}_{k}=\frac{1}{k} \sum_{i=1}^{k} z_{i}-h\left(x_{i \mid i}\right) \\
\hat{Q}_{k}=\frac{1}{k} \sum_{i=1}^{k}\left(x_{i \mid i}-f\left(x_{i-1 \mid i}\right)-q\right)\left(x_{i \mid i}-f\left(x_{i-1 \mid i}\right)-q\right)^{T} \\
\hat{R}_{k}=\frac{1}{k} \sum_{i=1}^{k}\left(z_{i}-h\left(x_{i \mid i}\right)-r\right)\left(z_{i}-h\left(x_{i \mid i}\right)-r\right)^{T}
\end{gathered}
$$

Although the suboptimal formulation relative to the noise statistics are calculated already, they contain the lack of estimates values, $x_{i-1 \mid i}$, which is unavailable from the original form of SVSF. For this reason, the SVSF is smoothed and improved using a one-step smoothing point [7], [15], [20]. Using Eq. (3) - Eq. (10), one lag smoothed values $\hat{x}_{k-1 \mid k}$ and its covariance $P_{k-1 \mid k}$ are computed as follows

$$
\begin{gathered}
\hat{x}_{k-1 \mid k}=\hat{x}_{k-1 \mid k-1}+K_{k}^{S V S F} \hat{e}_{z, k \mid k-1} \\
P_{k-1 \mid k}=\left(I-K_{k}^{S V S F} H\right) P_{k-1 \mid k-1}\left(I-K_{k}^{S V S F} H\right)^{T}+K_{k}^{S V S F} R_{k} K_{k}^{S V S F^{T}}
\end{gathered}
$$

Instead of using the prior $\hat{x}_{k-1 \mid k-1}$, in this point $\hat{x}_{k-1 \mid k}$ in Eq. (30) is applied into the transition function $\mathrm{f}($.$) in Eq. (3); then, the SVSF is essentially smoothed and improved already.$ Moreover, once Eq. (30) and Eq. (31) are determined, the estimated values $\hat{x}_{k \mid k}$ and $P_{k \mid k}$ can be computed. It is noted that the prediction steps in Eq. (3) and Eq. (4) of the second step are using the following definition.

$$
\hat{x}_{k \mid k-1}=f\left(\hat{x}_{k-1 \mid k}, u_{k}\right)+q
$$




$$
P_{k \mid k-1}=F P_{k-1 \mid k} F^{T}+Q
$$

Now, the estimate values $x_{i-1 \mid i}$ in the sequence forms of Eq. (22) - Eq. (25) can be replaced by Eq. (30).

\subsection{Unbiased Estimate Noise Statistic}

Up to this point, it seems to have clear derived formulation, but the simplification shown in Eq. (26) - Eq. (29) might reduce the quality as well as leads to bias condition. For this reason, the unbias estimation is approached to guarantee the optimality of Eq. (26) - Eq. (29). This stage can be sequentially conducted as follows; By definition, it is known that

$$
x_{i}-f\left(x_{i-1 \mid i}\right)=K_{i}^{S V S F} e_{z, i \mid i-1}+q
$$

Now, by substituting Eq. (34) into $z_{i}-h\left(x_{i \mid i}\right)$

$$
z_{i}-h\left(x_{i \mid i}\right)=z_{i}-h\left(x_{i \mid i-1}+K_{i}^{S V S F} e_{z, i \mid i-1}\right)=\left(I-H K_{i}^{S V S F}\right) e_{z, i \mid i-1}+r
$$

then the equivalent form of Eq. (26) - Eq. (29) are respectively presented as follows

$$
\begin{gathered}
\hat{q}_{k}=\frac{1}{k} \sum_{i=1}^{k} K_{i}^{S V S F} e_{z, i \mid i-1}+q \\
\hat{r}_{k}=\frac{1}{k} \sum_{i=1}^{k}\left(I-H K_{i}^{S V S F}\right) e_{z, i \mid i-1}+r \\
\hat{Q}_{k}=\frac{1}{k} \sum_{i=1}^{k} K_{i}^{S V S F} e_{z, i \mid i-1} e_{z, i \mid i-1}^{T} K_{i}^{S V S F}{ }^{T} \\
\hat{R}_{k}=\frac{1}{k} \sum_{i=1}^{k}\left(I-H K_{i}^{S V S F}\right) e_{z, i \mid i-1} e_{z, i \mid i-1}^{T}\left(I-H K_{i}^{S V S F}\right)^{T}
\end{gathered}
$$

Since the innovation $e_{z, k \mid k-1}$ and its covariance $e_{z, k \mid k-1} e_{z, k \mid k-1}^{T}$ are the parts on the process and measurement noise estimator, it is clear to have

$$
e_{z, i \mid i-1}=h\left(\tilde{x}_{i \mid i-1}\right)+v_{i}-r
$$

and the expectation of the innovation error $e_{z, k \mid k-1}$ as well as its corresponding covariance $e_{z, k \mid k-1} e_{z, k \mid k-1}^{T}$ are respectively obtained as follows

$$
\begin{gathered}
E\left[e_{z, k \mid k-1}\right]=0 \\
E\left[e_{z, k \mid k-1} e_{z, k \mid k-1}^{T}\right]=H P_{k \mid k-1} H^{T}+R
\end{gathered}
$$

Therefore, the expectation of all the suboptimal Eq. (36) - Eq. (39) are

$$
\begin{gathered}
E\left[\hat{q}_{k}\right]=q_{k} \\
E\left[\hat{r}_{k}\right]=r_{k}
\end{gathered}
$$


In order to obtain the expectation form of the error covariance noise statistic for both the process and measurement, the Joseph covariance form is used.

$$
P_{i \mid i}=P_{i \mid i-1}\left(I-K_{i}^{S V S F} H\right)=P_{i \mid i-1}-P_{i \mid i-1} K_{i}^{S V S F} H
$$

It is clear, once the unbiased estimates are also satisfiying $e_{z, i \mid i-1} e_{z, i \mid i-1}^{T}=H P_{i \mid i-1} H^{T}+R$, therefore, the following forms are determined

$$
\begin{gathered}
K_{i}^{S V S F} e_{z, i \mid i-1} e_{z, i \mid i-1}^{T}=H^{T} P_{i \mid i-1} \\
\left(K_{i}^{S V S F} e_{z, i \mid i-1} e_{z, i \mid i-1}^{T}\right)^{T}=H P_{i \mid i-1}
\end{gathered}
$$

Then all expectation values of $\theta$ relative to the error matrices are

$$
\begin{gathered}
E\left[\hat{Q}_{k}\right]=\frac{1}{k} \sum_{i=1}^{k}\left(F P_{i-1 \mid i-1} F^{T}+Q\right) H^{T} K_{i}^{S V S F^{T}} \\
E\left[\hat{R}_{k}\right]=R_{k}+\frac{1}{k} \sum_{i=1}^{k} H K_{i}^{S V S F} H P_{i \mid i-1} H^{T}-H P_{i \mid i-1} H^{T}
\end{gathered}
$$

Up to this point, the expectation of all the noise statistic are obtained. Note that, $q_{k}, r_{k}, Q_{k}, R_{k}$ in Eq. (46) - Eq. (49) and Eq. (36) - Eq. (39) are the representation of Eq. (26) Eq. (29), respectively. Hence, the unbiased noise statistic properties can be calculated as follows

$$
\begin{gathered}
\hat{q}_{k}=\frac{1}{k} \sum_{i=1}^{k} K_{i}^{S V S F} e_{z, i \mid i-1}+q \\
\hat{r}_{k}=\frac{1}{k} \sum_{i=1}^{k}\left(I-H K_{i}^{S V S F}\right) e_{z, i \mid i-1}+r \\
\left.\hat{Q}_{k}=\frac{1}{k} \sum_{i=1}^{k}\left(F P_{i-1 \mid i-1} F^{T}+K_{i}^{S V S F} e_{z, i \mid i-1} e_{z, i \mid i-1}^{T} K_{i}^{S V S F}\right)^{T}\right) H^{T} K_{i}^{S V S F} T \\
\hat{R}_{k}=\frac{1}{k} \sum_{i=1}^{k}\left(I-H K_{i}^{S V S F}\right) e_{z, i \mid i-1} e_{z, i \mid i-1}^{T}\left(I-H K_{i}^{S V S F}\right)^{T}-H P_{i \mid i-1} H^{T}+H K_{i}^{S V S F} H P_{i \mid i-1} H^{T} \\
=\frac{1}{k} \sum_{i=1}^{k}\left(I-H K_{i}^{S V S F}\right) e_{z, i \mid i-1} e_{z, i \mid i-1}^{T}\left(I-H K_{i}^{S V S F}\right)^{T} \\
-\left(I-H K_{i}^{S V S F}\right) H P_{i \mid i-1} H^{T}
\end{gathered}
$$

\subsection{Time-Varying Unbiased Noise Statistic}

Once, the unbiased form are calculated, the time-varying forms can also be calculated. According to Eq. (50) - Eq. (53), they are respectively expressed as follows

$$
\hat{q}_{k}=\hat{q}+\frac{1}{k}\left(K_{i}^{S V S F} e_{z, i \mid i-1}\right)
$$




$$
\begin{gathered}
\hat{r}_{k}=\hat{r}+\frac{1}{k}\left(\left(I-H K_{i}^{S V S F}\right) e_{z, i \mid i-1}\right) \\
\hat{Q}_{k}=\hat{Q} \frac{k-1}{k}+\frac{1}{k}\left(F P_{i-1 \mid i-1} F^{T}+K_{i}^{S V S F} e_{z, i \mid i-1} e_{z, i \mid i-1}^{T} K_{i}^{S V S F^{T}}\right) H^{T} K_{i}^{S V S F} \\
\hat{R}_{k}=\hat{R} \frac{k-1}{k}+\frac{1}{k}\left(\left(I-H K_{i}^{S V S F}\right) e_{z, i \mid i-1} e_{z, i \mid i-1}^{T}\left(I-H K_{i}^{S V S F}\right)^{T}-\left(I-H K_{i}^{S V S F}\right) H P_{i \mid i-1} H^{T}\right)
\end{gathered}
$$

where $\hat{q}, \hat{r}, \hat{Q}$, and $\hat{R}$ are $q_{k-1}, r_{k-1}, Q_{k-1}$, and $R_{k-1}$, respectively. Moreover, as an effort to keep its stability, the exponential $\frac{1}{k}$ in Eq. (54) - Eq. (57) are replaced with the weighting coefficient $d_{k}$ [7], [15], [18], [22], [30], [37]. Additionally, the use of Innovation Covariance Estimator (ICE) is involved to depress the posibility of negative definite matrices Eq. (56) Eq. (57). Then, the final formulation for covariance matrices relative to the noise statistic of the process and measurement are expressed as follows

$$
\begin{gathered}
\hat{Q}_{k}=\left(1-d_{k}\right) \hat{Q}_{k-1}+d_{k}\left(F P_{k-1 \mid k-1} F^{T}+K_{k}^{S V S F} I C E_{k} K_{k}^{S V S F^{T}}\right) H^{T} K_{k}^{S V S F}{ }^{T} \\
\hat{R}_{k}=\left(1-d_{k}\right) \hat{R}_{k-1}+d_{k}\left(\left(I-H K_{k}^{S V S F}\right) I C E_{k}\left(I-H K_{k}^{S V S F}\right)^{T}-\left(I-H K_{k}^{S V S F}\right) H P_{k \mid k-1} H^{T}\right)
\end{gathered}
$$

Once, the adaptive SVSF is designed with addition of the smoothing formulation (see Eq. (1) - Eq. (12) and Eq. (32) - Eq. (33)) and the time-varying of the noise statistic Eq. (54) Eq. (55) and Eq. (58) - Eq. (59), the adaptive SVSF-based SLAM algorihtm can also be designed. The design involves all the configuration and completeness that have been introduced in [15]. It is noted that this involvement includes the motion model, direct point-based observation, and inverse point-based observation. Accordingly, the compact pseduo-code of this algorithm can be described as follows:

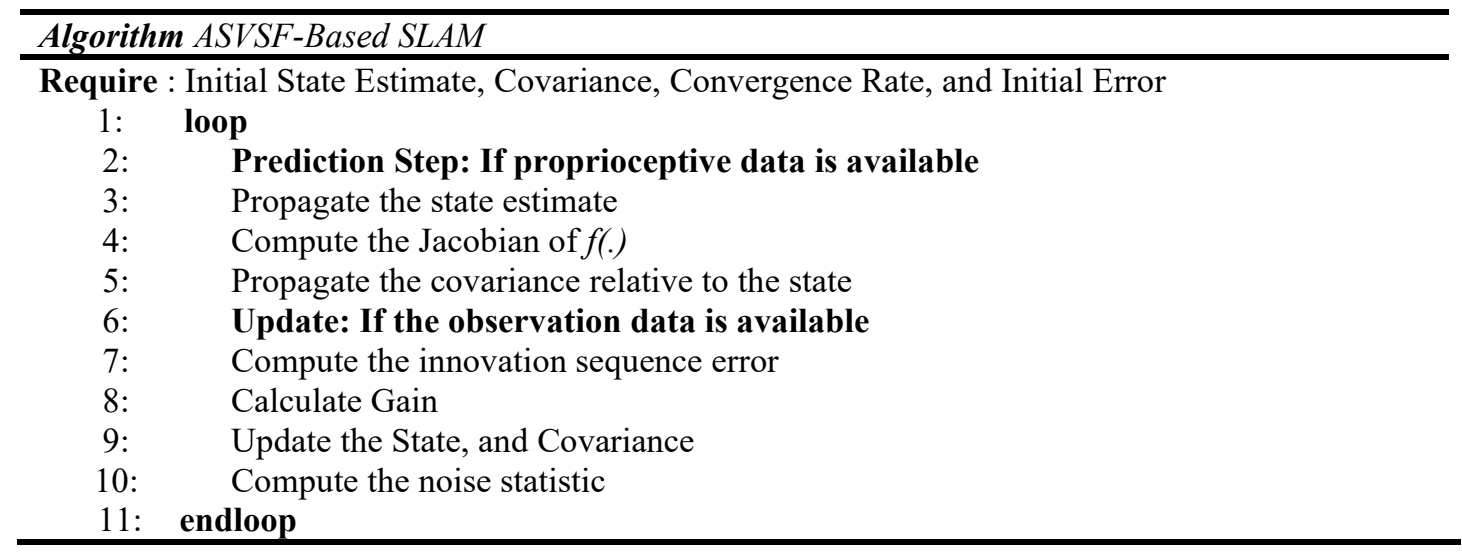

\section{RESULT AND DISCUSSION}

In order to validate its stability, the proposed method is realistically simulated before it is compared to the conventional one. All the parameters relative to the robot configuration are adopted from Turtlebot2, as stated below.

$$
W_{r}=33 \mathrm{~cm}, d_{l s}=14 \mathrm{~cm}, \gamma=15 e-2, e_{z, 0}=[0.1 ; 0.5 \pi / 180]
$$

Furthermore, the initial state and its error covariance are defined as follows. 


$$
\hat{x}_{0}=\left[\begin{array}{c}
0 \\
0 \\
\left(\frac{35 \pi}{180}\right)
\end{array}\right], P_{0}=\left[\begin{array}{ccc}
(1.5)^{2} & 0 & 0 \\
0 & 1^{2} & 0 \\
0 & 0 & \left(\frac{2.5 \pi}{180}\right)^{2}
\end{array}\right]
$$

It is also assumed, the robot is also completed with a 2D-LIDAR used to get the measurement data, distance and bearing. According to the initial noise statistics, there would be two different simulation cases presented in this paper.

- First Test The initial process and measurement noise are considered as follows

$$
\hat{q}_{0}=\left[\begin{array}{c}
0.03 \\
\left(\frac{\pi}{180}\right)
\end{array}\right], \hat{r}_{0}=\left[\begin{array}{c}
0.2 \\
\left(\frac{3 \pi}{180}\right)
\end{array}\right], \hat{Q}_{0}=\left[\begin{array}{cc}
0.03^{2} & 0 \\
0 & \left(\frac{\pi}{180}\right)^{2}
\end{array}\right], \hat{R}_{0}=\left[\begin{array}{cc}
0.2^{2} & 0 \\
0 & \left(\frac{3 \pi}{180}\right)^{2}
\end{array}\right]
$$

These noises will be executed once initially, and for the next iteration, they will be recursively provided by the proposed algorithm. To validate the effectiveness and robustness of the proposed method some comparative results are presented as follows.
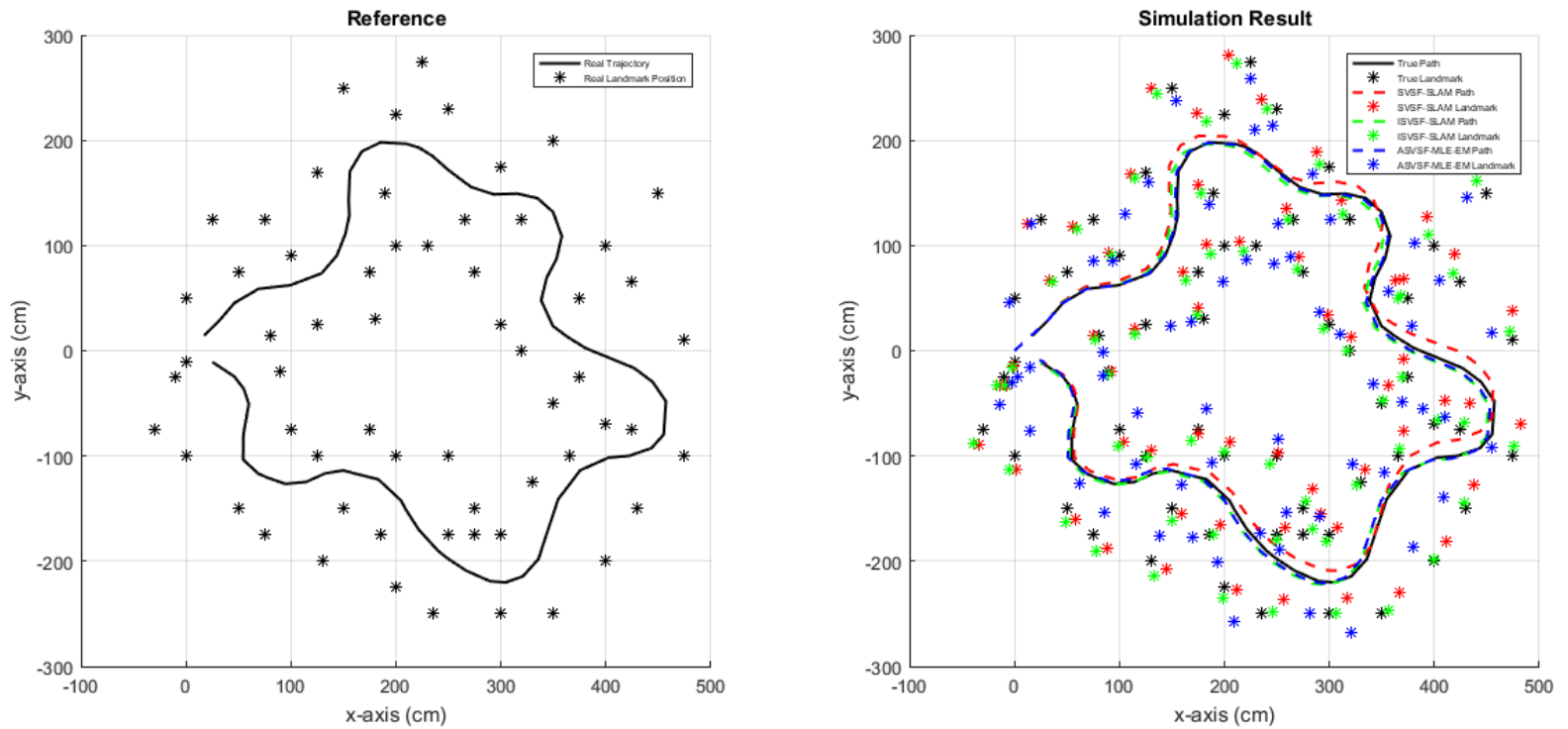

Fig. 1. Performance of Different SLAM-Based Algorithm (First Test)

Fig. 1 demonstrates different filter performances in solving the SLAM problem of wheeled mobile robots. It verifies that the proposed method's properness is satisfied with locating the robot position and mapping the features. Graphically, it is hard to evaluate the difference, so that Fig. 2 and Fig. 3 are presented.

Fig. 2 shows that the proposed method has been successfully presenting the better-estimated path than then SVSF-SLAM algorithm. Although the small difference between ISVSFSLAM, ASVSF-MLE-EM cannot be observed from this figure. So that to ease our analysis, Table 1 is presented.

Additionally, the algorithms mentioned above are also compared in terms of RMSE for the estimated map. Fig. 3 demonstrates that the proposed method has been reducing the RMSE given by the SVSF-SLAM algorithm. Thus, it can be noted that the ASVSF-SLAM based on MLE-EM has been successful in upgrading the quality of the classical method. 
Moreover, according to Fig. 3, the effectiveness of one-step smoothing has been proven to stably the SVSF-SLAM algorithm.
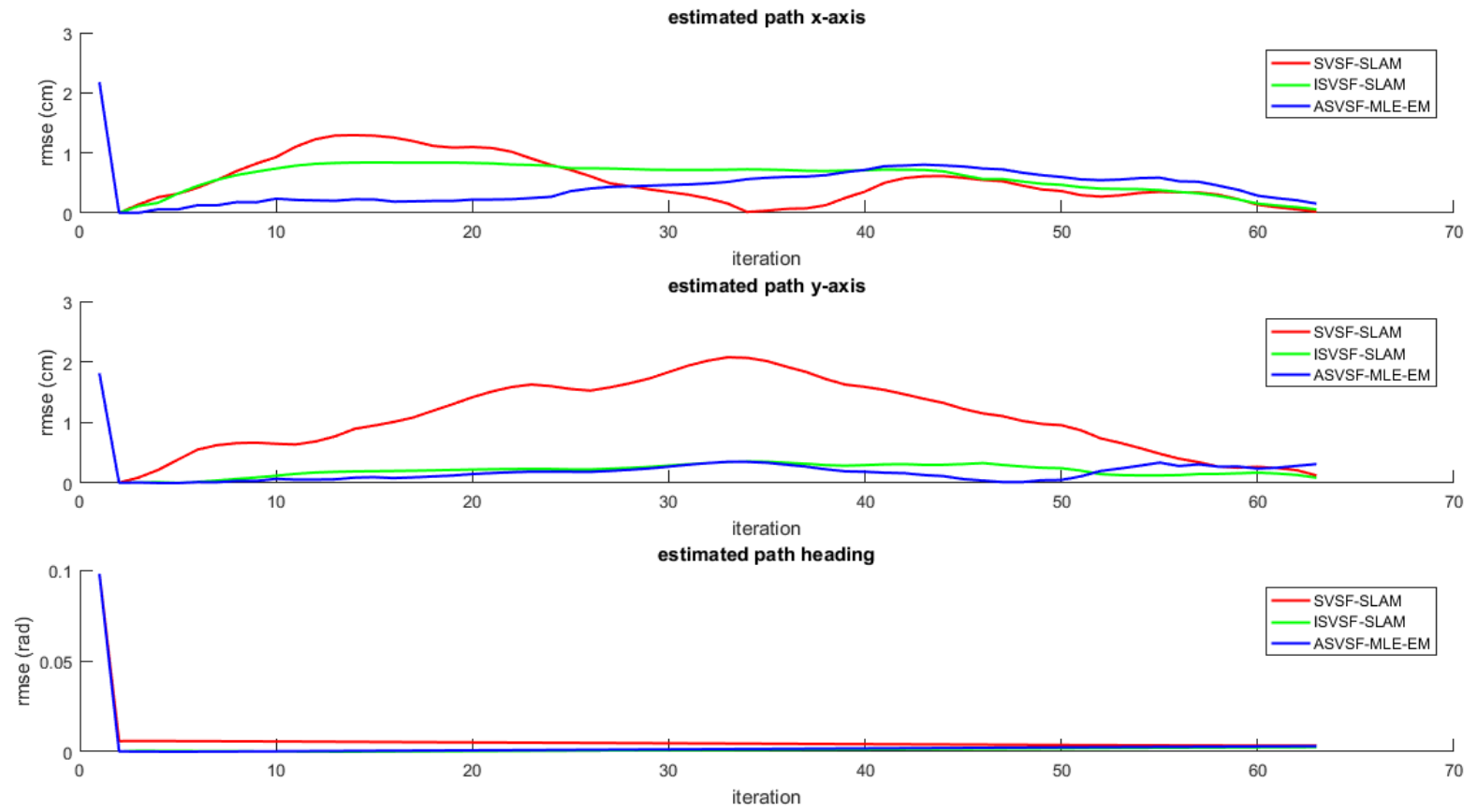

Fig. 2. RMSE of Estimated Path Coordinate of Different SLAM-Algorithm (First Test)
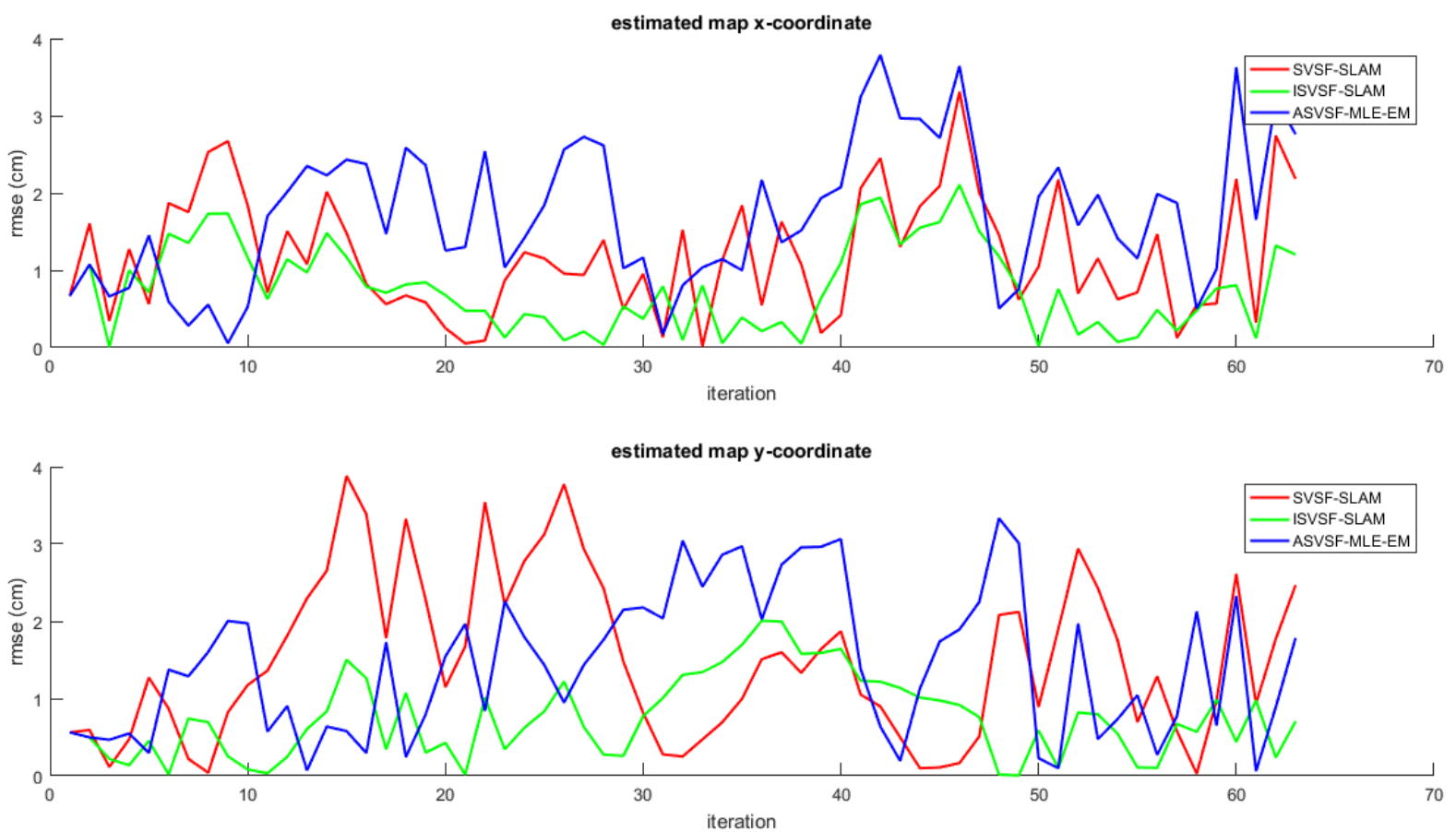

Fig. 3. RMSE of Estimated Map Coordinate of Different SLAM-Algorithm (First Test) 
Table 1: RMSE of Different SLAM-Based Algorithm (First Test)

\begin{tabular}{cccccc}
\hline $\begin{array}{c}\text { SLAM-Based } \\
\text { Algorithm }\end{array}$ & $\begin{array}{c}\mathbf{x} \text {-EPC } \\
{[\mathbf{c m}]}\end{array}$ & $\begin{array}{c}\text { y-EPC } \\
{[\mathbf{c m}]}\end{array}$ & $\begin{array}{c}\boldsymbol{\theta} \text {-EPC } \\
{[\mathbf{r a d}]}\end{array}$ & $\begin{array}{c}\text { x-EMC } \\
{[\mathbf{c m}]}\end{array}$ & $\begin{array}{c}\text { y-EMC } \\
{[\mathbf{c m}]}\end{array}$ \\
\hline SVSF & 5.5823 & 9.7952 & 0.1045 & 11.2296 & 14.4148 \\
ISVSF & 5.4492 & 2.5447 & 0.0985 & 7.5200 & 14.2128 \\
ASVSF & 4.2798 & 2.3807 & 0.0989 & 15.4925 & 13.5943 \\
\hline
\end{tabular}

- Second Test The initial process and measurement noise are considered as follows.

$$
\hat{q}_{0}=\left[\begin{array}{c}
0.08 \\
\left(\frac{5 \pi}{180}\right)
\end{array}\right], \hat{r}_{0}=\left[\begin{array}{c}
0.8 \\
\left(\frac{3 \pi}{180}\right)^{2}
\end{array}\right], \hat{Q}_{0}=\left[\begin{array}{cc}
0.08^{2} & 0 \\
0 & \left(\frac{5 \pi}{180}\right)^{2}
\end{array}\right], \hat{R}_{0}=\left[\begin{array}{cc}
0.8^{2} & 0 \\
0 & \left(\frac{3 \pi}{180}\right)^{2}
\end{array}\right]
$$

In the second case, the initial noise statistics both for process and measurement were increased. It aims to examine the stability of the proposed algorithm under an uncertain predetermined noise statistic.
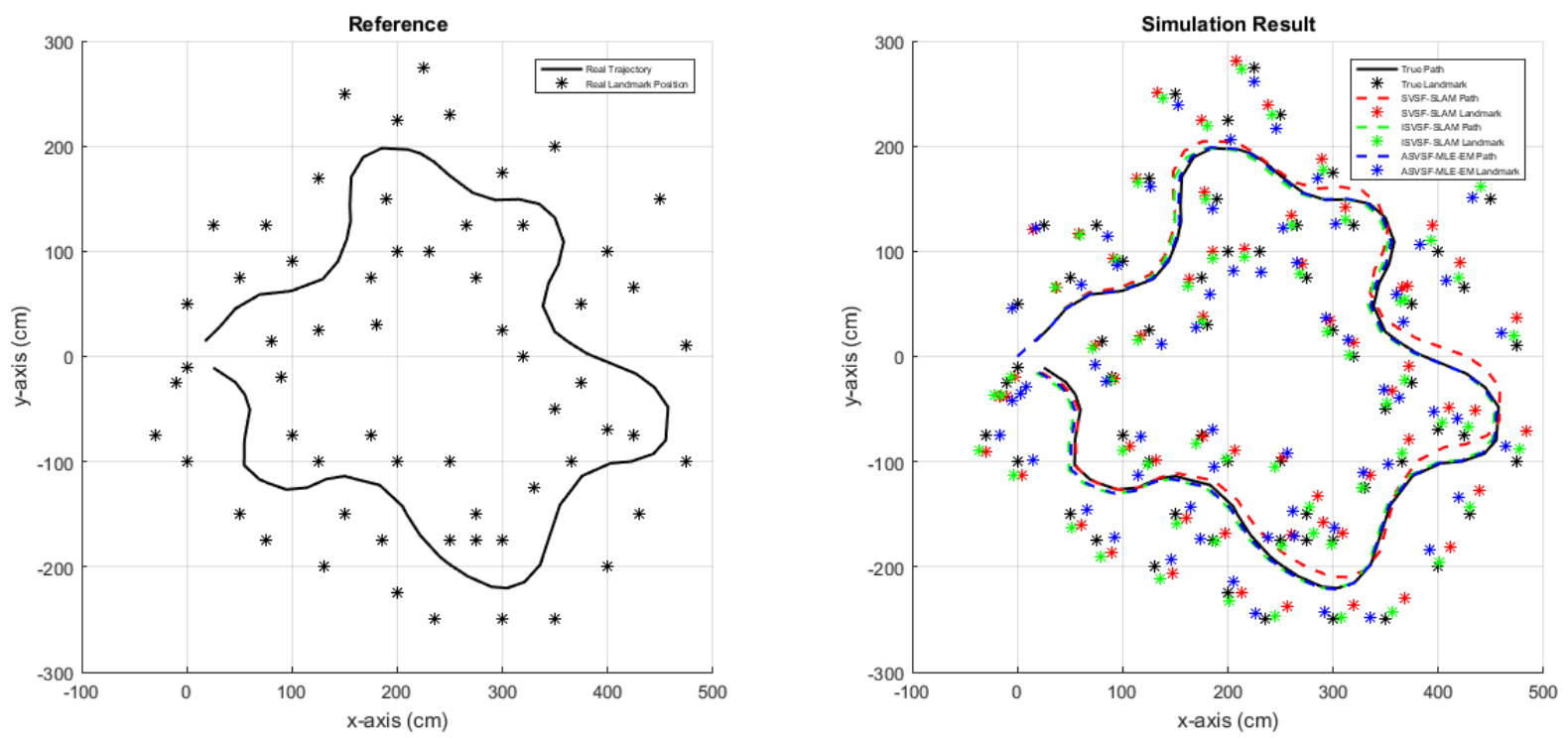

Fig. 4. Performance of Different SLAM-Based Algorithm (Second Test)

Similarly, Fig. 4 also demonstrates different filter performances in solving the SLAM problem of wheeled mobile robots. It also verifies that the proposed method's properness is satisfied with locating the robot position and mapping the features even there is an increment of small additive noise to both the process and measurement.

According to Fig. 5, it can be noted that the increment of the defined noise statistic has no effect on the proposed method stability. It is shown by its ability to reduce RMSE of the SVSF-SLAM algorithm. At this point, it can be stated that the proposed method can guarantees stability better than the classical one. Next, to validate the proposed algorithm stability, the different approaches in estimating map are compared (see Fig. 6).

Fig. 6 illustrates that the stability of the proposed method in mapping the feature is satisfied even after increasing the statistics of the initial noise. According to Fig. 6, the proposed method also presents better quality compared with the SVSF-SLAM algorithm. The 
effectiveness of one-smoothing is again proven, referring to its best achievement in estimating the map. Similarly, to clearance the differences in the simulation results discussed above, Table 2 is presented.
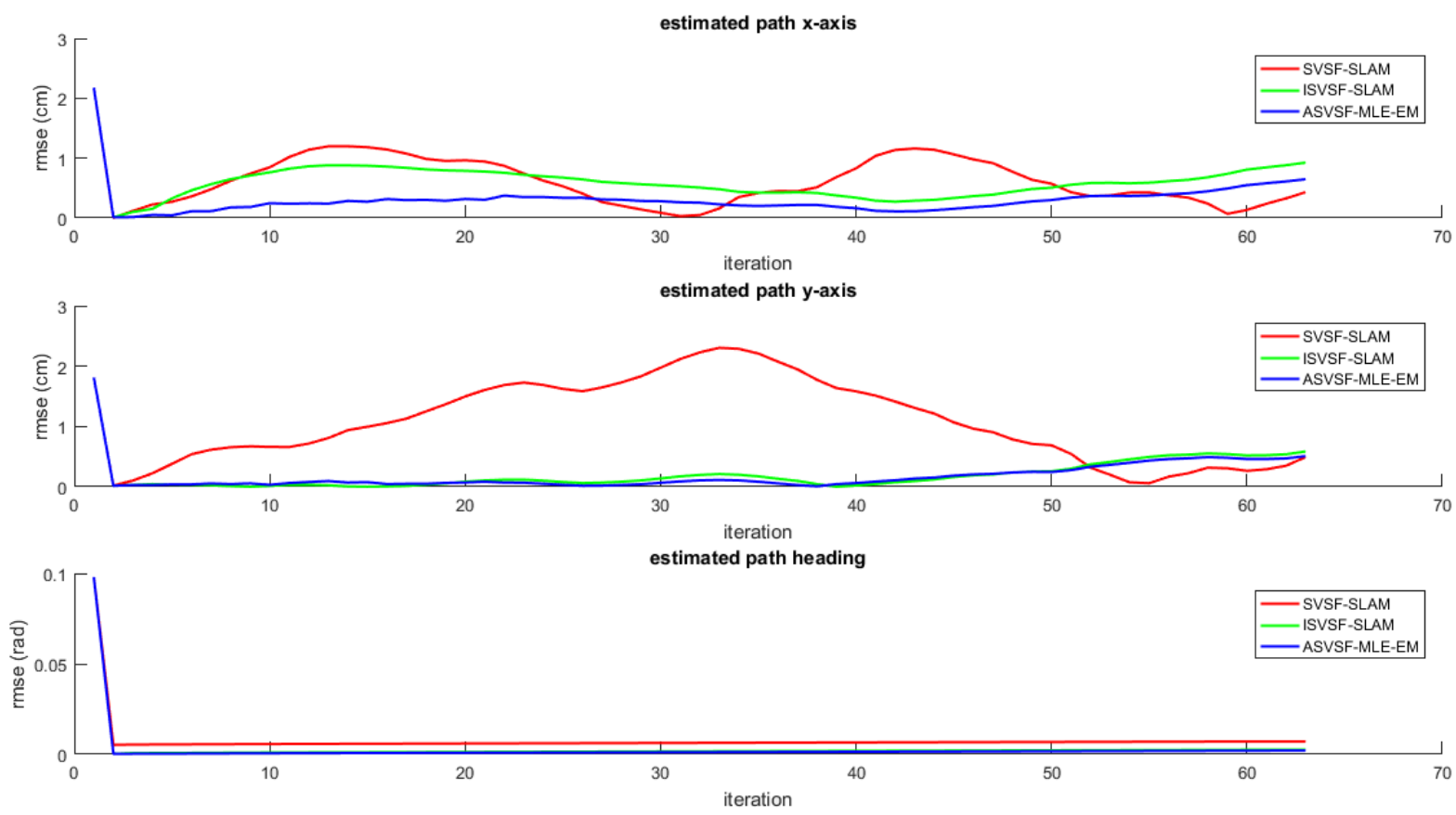

Fig. 5 RMSE of Estimated Path Coordinate of Different SLAM-Algorithm (Second Test)
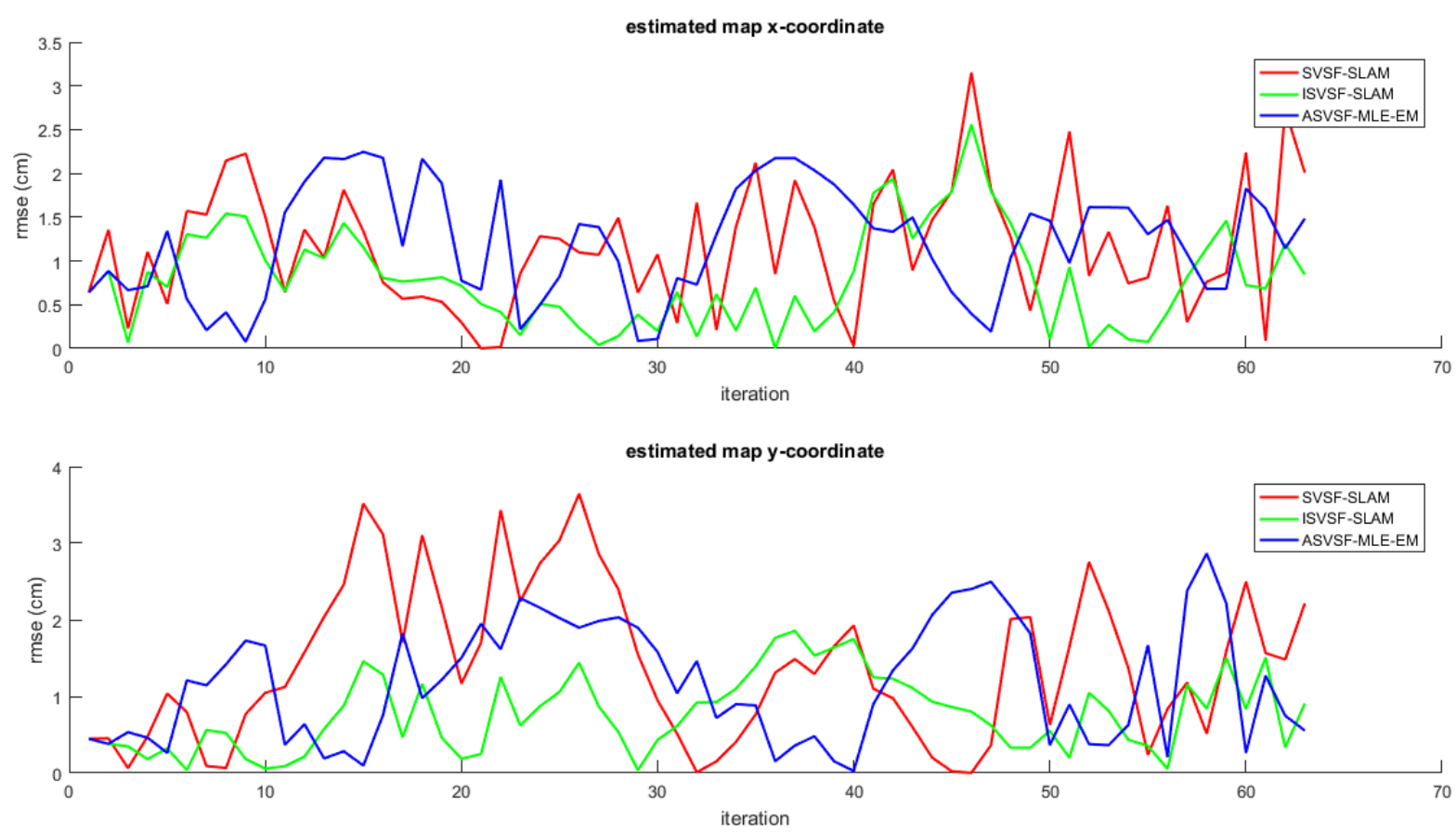

Fig. 6. RMSE of Estimated Map Coordinate of Different SLAM-Algorithm (Second Test) 
Table 2: RMSE of Different SLAM-Based Algorithm (Second Test)

\begin{tabular}{cccccc}
\hline $\begin{array}{c}\text { SLAM-Based } \\
\text { Algorithm }\end{array}$ & $\begin{array}{c}\mathbf{x - E P C} \\
{[\mathbf{c m}]}\end{array}$ & $\begin{array}{c}\mathbf{y} \text {-EPC } \\
{[\mathbf{c m}]}\end{array}$ & $\begin{array}{c}\boldsymbol{\theta} \text {-EPC } \\
{[\mathbf{r a d}]}\end{array}$ & $\begin{array}{c}\mathbf{x - E M C} \\
{[\mathbf{c m}]}\end{array}$ & $\begin{array}{c}\mathbf{y - E M C} \\
{[\mathbf{c m}]}\end{array}$ \\
\hline SVSF & 5.9065 & 10.0448 & 0.1099 & 10.8078 & 13.6891 \\
ISVSF & 5.3109 & 2.6691 & 0.0989 & 7.7296 & 7.2725 \\
ASVSF & 3.2337 & 2.5043 & 0.0985 & 10.8512 & 11.1995 \\
\hline
\end{tabular}

According to Table 1 and Table 2, the smallest RMSE is shown by the ISVSF-Based SLAM algorithm. It verifies that the one-step smoothing technique has been successfully enhancing the classical SVSF without losing the SVSF characteristic. However, since it can estimate the noise statistic, its performance cannot guarantee effectiveness when applied in the real application. Regarding these differences, the proposed method has been presenting excellent performance.

- Third Test ASVSF-SLAM Algorithm Based on MLE-EM with and without ICE

In order to evaluate the existence of Innovation Covariance Estimation, the following figures (see Fig. 7 and Fig. 8) are presented. These results refer to the initial noise statistic as defined in the Second Test above.
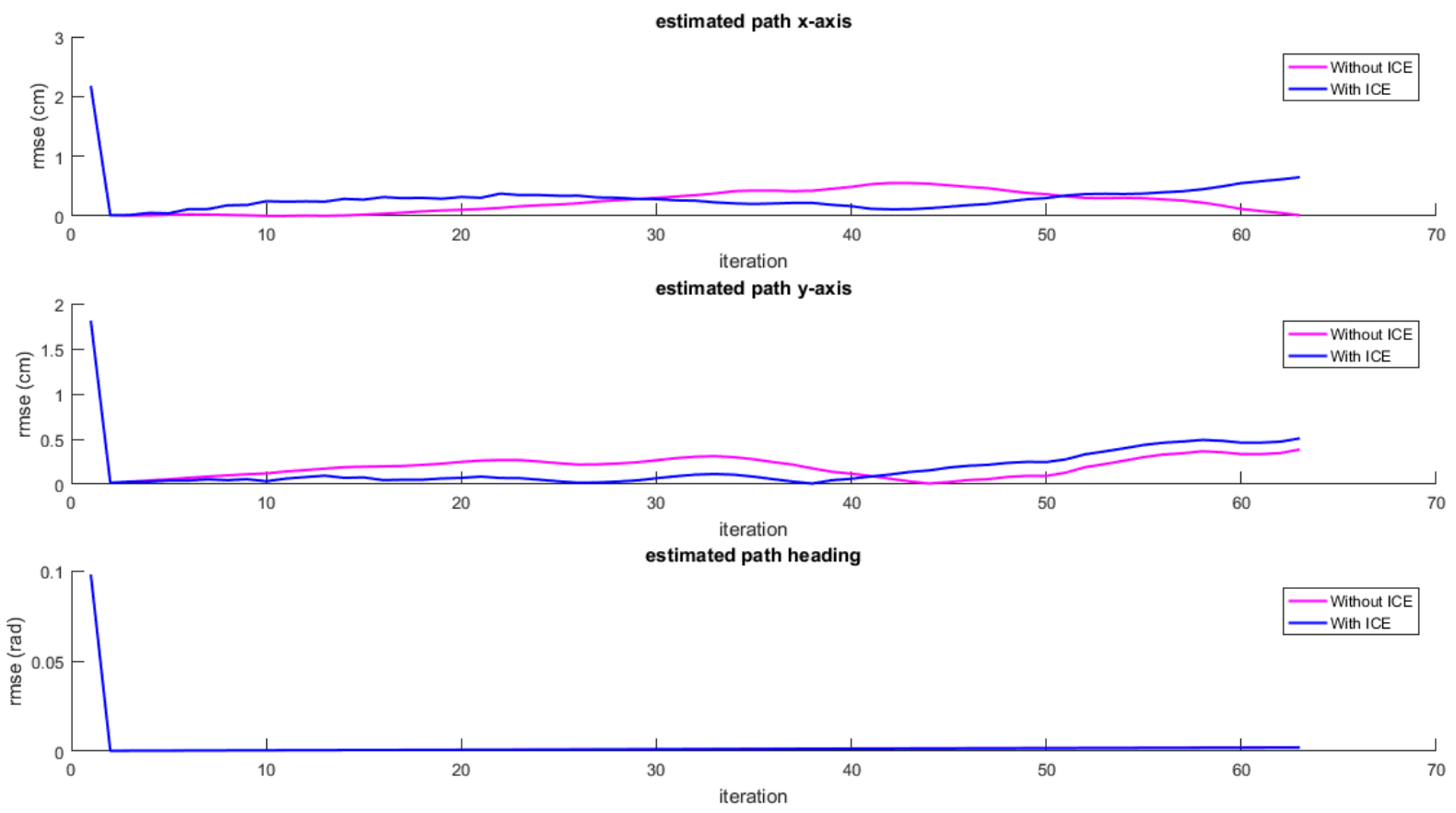

Fig. 7. RMSE of Estimated Path Coordinate of Different SLAM-Algorithm (Third Test)

Fig.7 confirms that the simplification of the first formulated covariance of the measurement noise statistic does not negatively affect the final solution. It can be proven as well in Fig. 8. 

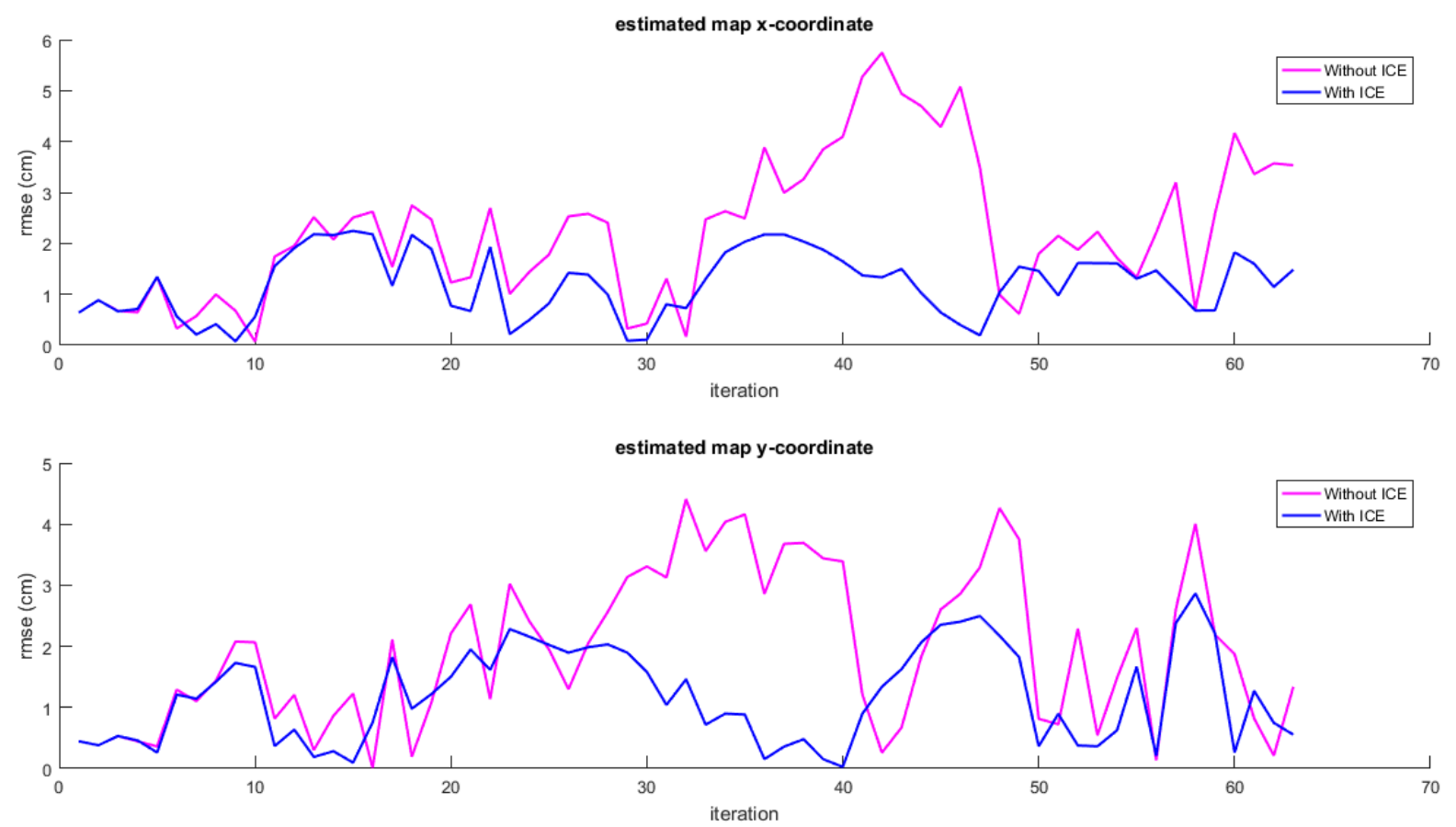

Fig. 8. RMSE of Estimated Map Coordinate of Different SLAM-Algorithm (Third Test)

At this point, it can be noted that the differences depicted by Fig. 7 and Fig. 8 verify that the Innovation Covariance Estimator (ICE) has been successfully reducing RMSE of the original ASVFV-SLAM algorithm. To ease our analysis, Table 3 is also presented

Table 3: RMSE of Different SLAM-Based Algorithm (Second Test)

\begin{tabular}{cccccc}
\hline $\begin{array}{c}\text { ASVSF- } \\
\text { SLAM-Based } \\
\text { Algorithm }\end{array}$ & $\begin{array}{c}\mathbf{x - E P C} \\
{[\mathbf{c m}]}\end{array}$ & $\begin{array}{c}\mathbf{y - E P C} \\
{[\mathbf{c m}]}\end{array}$ & $\begin{array}{c}\boldsymbol{\theta} \text {-EPC } \\
{[\mathbf{r a d}]}\end{array}$ & $\begin{array}{c}\mathbf{x - E M C} \\
{[\mathbf{c m}]}\end{array}$ & $\begin{array}{c}\mathbf{y} \text {-EMC } \\
{[\mathbf{c m}]}\end{array}$ \\
\hline Without ICE & 3.1637 & 2.4950 & 0.0985 & 20.9206 & 18.3115 \\
With ICE & 3.2337 & 2.3807 & 2.5043 & 10.8512 & 11.1995 \\
\hline
\end{tabular}

According to Table 3, the proposed method with ICE has been showing better performance compared to other algorithm in term of RMSE of EPC and EMC

\section{CONCLUSION}

This paper presents a proposed method termed as ASVSF-SLAM Based on MLE-EM creation. The contributions can be summarized as follows; improving the normal SVSF based on a one-step smoothing method, providing an ability to estimate the noise statistic to normal SVSF, providing the time-varying unbiased noise statistic; completing the recursive unbiased noise statistic with innovation covariance estimation. Following all the stages and validating the ASVSF-SLAM algorithm's performance in terms of RMSE has been proving the robustness and effectiveness of the proposed method. Additionally, by referring to the convergence result, which is shown by its performance in different and increment of the initially predetermined noise statistic, the proposed method guarantees the stability compared to the conventional one. 


\section{ACKNOWLEDGEMENT}

Research was supported by Special Plan of Major Scientific Instruments and Equipment of the State (Grant No.2018YFF01013101), National Natural Science Foundation of China (61704102), the IIOT Innovation and Development Special Foundation of Shanghai (2017GYHLW01037) and Project named "Key Technology Research and Demonstration Line Construction of Advanced Laser Intelligent Manufacturing Equipment" from Shanghai Lingang Area Development Administration, Shanghai University, and Mercu Buana University, Jakarta, Indonesia.

\section{REFERENCES}

[1] Suwoyo, H., Tian, Y., Deng, C., \& Adriansyah, A. (2018). Improving a Wall-Following Robot Performance with a PID-Genetic Algorithm Controller. Proceeding of the Electrical Engineering Computer Science and Informatics, 5(1), 314-318.

[2] Adriansyah, A., Suwoyo, H., \& Tian, Y. (2019). Jurnal Teknologi IMPROVING ROBOT. 3, 119-126.

[3] Afshari, H. H., Gadsden, S. A., \& Habibi, S. (2017). Gaussian filters for parameter and state estimation: A general review of theory and recent trends. Signal Processing. https://doi.org/10.1016/j.sigpro.2017.01.001

[4] Ahmed, R., El Sayed, M., Gadsden, S. A., Tjong, J., \& Habibi, S. (2016). Artificial neural network training utilizing the smooth variable structure filter estimation strategy. Neural Computing and Applications, 27(3), 537-548. https://doi.org/10.1007/s00521-015-1875-2

[5] Akhlaghi, S., Zhou, N., \& Huang, Z. (2018). Adaptive adjustment of noise covariance in Kalman filter for dynamic state estimation. IEEE Power and Energy Society General Meeting, 2018January, 1-5. https://doi.org/10.1109/PESGM.2017.8273755

[6] Al-Shabi, M., \& Habibi, S. (2011). Iterative smooth variable structure filter for parameter estimation. ISRN Signal Processing, 2011(1). https://doi.org/10.5402/2011/725108

[7] Bailey, T. (2002). Mobile Robot Localisation and Mapping in Extensive Outdoor Environments. Philosophy, 31(August), 212. https://doi.org/10.1016/S0921-8890(99)00078-0

[8] Bailey, T., \& Durrant-whyte, H. (n.d.). Simultaneous Localisation and Mapping ( SLAM ): Part II State of the Art. 1-10.

[9] Bar-Shalon, Y., Li, X.-R., \& Kirubarajan, T. (n.d.). Estimation with Applications to Tracking and Navigation.

[10] Benzerrouk, H., Nebylov, A., \& Salhi, H. (2016). Quadrotor UAV state estimation based on HighDegree Cubature Kalman filter. IFAC-PapersOnLine. https://doi.org/10.1016/j.ifacol.2016.09.060

[11] Chen, S., Shi, Z., \& Ding, J. (2017). Application of the 2nd-order Smooth Variable Structure Filter algorithm for SINS initial alignment. 2017 Forum on Cooperative Positioning and Service, CPGPS 2017, (1), 43-49. https://doi.org/10.1109/CPGPS.2017.8075095

[12] Choset, H., Lynch, K., Hutchinson, S., Kantor, G., Burgard, W., Kavraki, L., \& Thrun, S. (2006). PRINCIPLES OF ROBOT MOTION, Theory, Algorithms and Implementations, by Howie Choset et al., MIT Press, 2005. xix + 603 pp., index, ISBN 0-262-03327-5, 433 references (Hb. $£ 38.95)$. Robotica, 24(2), 271-271. https://doi.org/10.1017/s0263574706212803

[13] Demim, F., Nemra, A., \& Louadj, K. (2016). Robust SVSF-SLAM for Unmanned Vehicle in Unknown Environment. IFAC-PapersOnLine. https://doi.org/10.1016/j.ifacol.2016.10.585

[14] Fethi, D., Nemra, A., Louadj, K., \& Hamerlain, M. (2018). Simultaneous localization, mapping, and path planning for unmanned vehicle using optimal control. Advances in Mechanical Engineering, 10(1), 1-25. https://doi.org/10.1177/1687814017736653

[15] Gadsden, S. A., Al-Shabi, M., Arasaratnam, I., \& Habibi, S. R. (2014). Combined cubature Kalman and smooth variable structure filtering: A robust nonlinear estimation strategy. Signal Processing, 96 (PART B), 290-299. https://doi.org/10.1016/j.sigpro.2013.08.015

[16] Gadsden, S. Andrew, \& Afshari, H. H. (2015). A review of smooth variable structure filters: Recent advances in theory and applications. ASME International Mechanical Engineering 
Congress and Exposition, Proceedings (IMECE), 4A-2015. https://doi.org/10.1115/IMECE201550966

[17] Gadsden, S. Andrew, Habibi, S. R., Dunne, D., \& Kirubarajan, T. (2011). Combined particle and smooth variable structure filtering for nonlinear estimation problems. Fusion 2011 - 14th International Conference on Information Fusion, 1552-1559.

[18] Gadsden, S. Andrew, \& Lee, A. S. (2017). Advances of the smooth variable structure filter: square-root and two-pass formulations. Journal of Applied Remote Sensing. https://doi.org/10.1117/1.jrs.11.015018

[19] Gadsden, Stephen Andrew. (2011). Smooth Variable Structure Filter Theory and Application.pdf. McMaster University.

[20] Gao, B., Gao, S., Gao, L., \& Hu, G. (2016). An adaptive UKF for nonlinear state estimation via maximum likelihood principle. ICEIEC 2016 - Proceedings of 2016 IEEE 6th International Conference on Electronics Information and Emergency Communication, (4), 117-120. https://doi.org/10.1109/ICEIEC.2016.7589701

[21] Gao, B., Gao, S., Hu, G., Zhong, Y., \& Gu, C. (2018). Maximum likelihood principle and moving horizon estimation based adaptive unscented Kalman filter. Aerospace Science and Technology. https://doi.org/10.1016/j.ast.2017.12.007

[22] Gao, W., Li, J., Zhou, G., \& Li, Q. (2015). Adaptive Kalman filtering with recursive noise estimator for integrated SINS/DVL systems. Journal of Navigation, 68(1), 142-161. https://doi.org/10.1017/S0373463314000484

[23] Gao, Z., Mu, D., Zhong, Y., Gu, C., \& Ren, C. (2019). Adaptively random weighted cubature kalman filter for nonlinear systems. Mathematical Problems in Engineering, 2019. https://doi.org/10.1155/2019/4160847

[24] Grisetti, G. (2004). Towards a PhD Thesis on Simultaneous Localization and Mapping. 1-38. Retrieved from http://citeseerx.ist.psu.edu/viewdoc/download?doi=10.1.1.106.4683\&amp;rep=rep1\&amp;type $=\mathrm{pdf}$

[25] Habibi, B. S. (2007). Structure Filter. Proceedings of the IEEE, 95(5).

[26] He, J., Chen, Y., Zhang, Z., Yin, W., \& Chen, D. (2018). A hybrid adaptive unscented Kalman filter algorithm. International Journal for Engineering Modelling, 31(3), 51-65. https://doi.org/10.31534/engmod.2018.3.ri.04d

[27] Huang, Y., Zhang, Y., Xu, B., Wu, Z., \& Chambers, J. A. (2018). A New Adaptive Extended Kalman Filter for Cooperative Localization. IEEE Transactions on Aerospace and Electronic Systems, 54(1), 353-368. https://doi.org/10.1109/TAES.2017.2756763

[28] Kim, K. H., Lee, J. G., \& Park, C. G. (2009). Adaptive two-stage extended kalman filter for a fault-tolerant INS-GPS loosely coupled system. IEEE Transactions on Aerospace and Electronic Systems, 45(1), 125-137. https://doi.org/10.1109/TAES.2009.4805268

[29] Kim, T., Wang, Y., Sahinoglu, Z., Wada, T., Hara, S., \& Qiao, W. (2014). State of charge estimation based on a realtime battery model and iterative smooth variable structure filter. 2014 IEEE Innovative Smart Grid Technologies - Asia, ISGT ASIA 2014, 132-137. https://doi.org/10.1109/ISGT-Asia.2014.6873777

[30] LaViola, J. J. (2003). A Comparison of Unscented and Extended Kalman Filtering for Estimating Quaternion Motion. Proceedings of the American Control Conference, 3, 2435-2440.

[31] Levitan, E., \& Herman, G. T. (1987). A Maximum A Posteriori Probability Expectation Maximization Algorithm for Image Reconstruction in Emission Tomography. IEEE Transactions on Medical Imaging, 6(3), 185-192. https://doi.org/10.1109/TMI.1987.4307826

[32] Li, Z., Yang, W., \& Ding, D. (2017). Time-Varying Noise Statistic Estimator Based Adaptive Simplex Cubature Kalman Filter. Mathematical Problems in Engineering, 2017. https://doi.org/10.1155/2017/5349879

[33] Mohamed, A. H., \& Schwarz, K. P. (1999). Adaptive Kalman filtering for INS/GPS. Journal of Geodesy, 73(4), 193-203. https://doi.org/10.1007/s001900050236

[34] Outamazirt, F., Fu, L., Lin, Y., \& Abdelkrim, N. (2016). A new SINS/GPS sensor fusion scheme for UAV localization problem using nonlinear SVSF with covariance derivation and an adaptive boundary layer. Chinese Journal of Aeronautics. https://doi.org/10.1016/j.cja.2016.02.005 
[35] Shao, X., He, B., Guo, J., \& Yan, T. (2016). The application of AUV navigation based on adaptive extended Kalman filter. OCEANS 2016 - Shanghai. https://doi.org/10.1109/OCEANSAP.2016.7485592

[36] Suwoyo, H., Deng, C., Tian, Y., \& Adriansyah, A. (2018). Improving a wall-following robot performance with a PID-genetic algorithm controller. International Conference on Electrical Engineering, Computer Science and Informatics (EECSI), 2018-Octob, 314-318. https://doi.org/10.1109/EECSI.2018.8752907

[37] Thrun, S. (2002). Probabilistic robotics. Communications of the ACM, 45(3), 52-57. https://doi.org/10.1145/504729.504754

[38] Tian, Y., Suwoyo, H., Wang, W., \& Li, L. (2019). An ASVSF-SLAM Algorithm with TimeVarying Noise Statistics Based on MAP Creation and Weighted Exponent. Mathematical Problems in Engineering, 2019, 28-34. https://doi.org/10.1155/2019/2765731

[39] Tian, Y., Suwoyo, H., Wang, W., Mbemba, D., \& Li, L. (2019). An AEKF-SLAM Algorithm with Recursive Noise Statistic Based on MLE and EM. Journal of Intelligent and Robotic Systems: Theory and Applications. https://doi.org/10.1007/s10846-019-01044-8

[40] Wan, E. A., \& Van Der Merwe, R. (2000). The unscented Kalman filter for nonlinear estimation. IEEE 2000 Adaptive Systems for Signal Processing, Communications, and Control Symposium, AS-SPCC 2000, 153-158. https://doi.org/10.1109/ASSPCC.2000.882463

[41] Wang, Hairong, Deng, Z., Feng, B., Ma, H., \& Xia, Y. (2017). An adaptive Kalman filter estimating process noise covariance. https://doi.org/10.1016/j.neucom.2016.10.026

[42] Wang, Hongjian, Fu, G., Li, J., Yan, Z., \& Bian, X. (2013). An adaptive UKF based SLAM method for unmanned underwater vehicle. Mathematical Problems in Engineering, 2013. https://doi.org/10.1155/2013/605981

[43] Wang, X., Song, B., Liang, Y., \& Pan, Q. (2017). EM-based adaptive divided difference filter for nonlinear system with multiplicative parameter. International Journal of Robust and Nonlinear Control, 27(13), 2167-2197. https://doi.org/10.1002/rnc.3674

[44] Woo, R., Yang, E. J., \& Seo, D. W. (2019). A fuzzy-innovation-based adaptive Kalman filter for enhanced vehicle positioning in dense urban environments. Sensors (Switzerland), 19(5). https://doi.org/10.3390/s19051142

[45] Yang, J. N., Pan, S., \& Huang, H. (2007). An adaptive extended Kalman filter for structural damage identifications II: Unknown inputs. Structural Control and Health Monitoring, 14(3), 497-521. https://doi.org/10.1002/stc. 171

[46] Yang, Jann N., Lin, S., Huang, H., \& Zhou, L. (2006). An adaptive extended Kalman filter for structural damage identification. Structural Control and Health Monitoring, 13(4), 849-867. https://doi.org/10.1002/stc.84

[47] Yi, B., Kang, L., Tao, S., Zhao, X., \& Jing, Z. (2013). Adaptive two-stage extended kalman filter theory in application of sensorless control for permanent magnet synchronous motor. Mathematical Problems in Engineering, 2013. https://doi.org/10.1155/2013/974974

[48] Yong, S., Chongzhao, H., \& Yongqi, L. (2009). Adaptive UKF for target tracking with unknown process noise statistics. 2009 12th International Conference on Information Fusion, FUSION 2009, (1), 1815-1820.

[49] Yu, F., Sun, Q., Lv, C., Ben, Y., \& Fu, Y. (2014). A SLAM algorithm based on adaptive cubature Kalman filter. Mathematical Problems in Engineering, 2014. https://doi.org/10.1155/2014/171958

[50] Zeng, Z., Zhang, S., Xing, Y., \& Cao, X. (2014). Robust adaptive filter for small satellite attitude estimation based on magnetometer and gyro. Abstract and Applied Analysis, 2014. https://doi.org/10.1155/2014/159149 